\title{
CONHECIMENTO PROBABILÍSTICO DE CRIANÇAS: UMA ANÁLISE CONSIDERANDO O JOGO TRAVESSIA DO RIO
}

\author{
Rita Batista e Rute Borba \\ Universidade Federal de Pernambuco - UFPE - EDUMATEC, Brasil \\ ritamat@hotmail.com
}

O presente estudo é um recorte de uma pesquisa sobre o conhecimento probabilístico de crianças, utilizando jogos. Expomos as análises realizadas a partir de uma entrevista clínica com três crianças utilizando o jogo Travessia do Rio (Brasil, 2014). O jogo tem como objetivo analisar a possibilidade de soma no lançamento de dois dados. Nosso foco circundou, especialmente, duas exigências cognitivas necessárias à compreensão da probabilidade: compreender a aleatoriedade e formar o espaço amostral (Bryant e Nunes, 2012). Os resultados apontaram que os participantes não demonstraram familiaridade/domínio sobre o espaço amostral. A aleatoriedade foi associada a uma vontade ou escolha pessoal. No que diz respeito à independência de eventos, as crianças cometeram o erro de recência positiva ou recência negativa. Percebemos, apoiados também em outros estudos, a necessidade de intervenção escolar para ampliação da compreensão probabilística das crianças.

\section{INTRODUÇÃO}

Nossa pesquisa versa sobre o conhecimento probabilístico de crianças em situações de jogos e está ancorada nas exigências cognitivas apontadas por Bryant e Nunes (2012) que defendem que para a compreensão da probabilidade é necessário o desenvolvimento de quatro exigências cognitivas

- A compreensão da natureza e das consequências da aleatoriedade;

- A formação e a categorização do espaço amostral;

- A comparação e a quantificação de probabilidades;

- O entendimento de correlações.

O recorte apontado neste artigo diz respeito à análise de um dos jogos utilizados como piloto para o desenvolvimento da pesquisa supracitada.

Focaremos o jogo Travessia do Rio, presente no caderno de jogos do Pacto Nacional para Alfabetização na Idade Certa - PNAIC (Brasil, 2014). O jogo simula um rio que tem no seu entorno a numeração de 1 a $12 \mathrm{em}$ cada uma das margens, como ilustrado abaixo. Os objetivos do jogo apresentados na proposta do PNAIC são resolver adições e analisar possibilidades de soma 2, $3,4,5,6,7,8,9,10,11$ e 12 no lançamento de dois dados.

Luvison e Santos (2013) propõem uma atividade fazendo uso do jogo Travessia do Rio e esclarecem que o jogo foi produzido pela Associação de Professores de Matemática de Portugal (APM). a fim de trabalhar questões que envolvem a Estatística e a Probabilidade.

JOGO TRAVESSIA DO RIO (Brasil, 2014, p. 40-41)
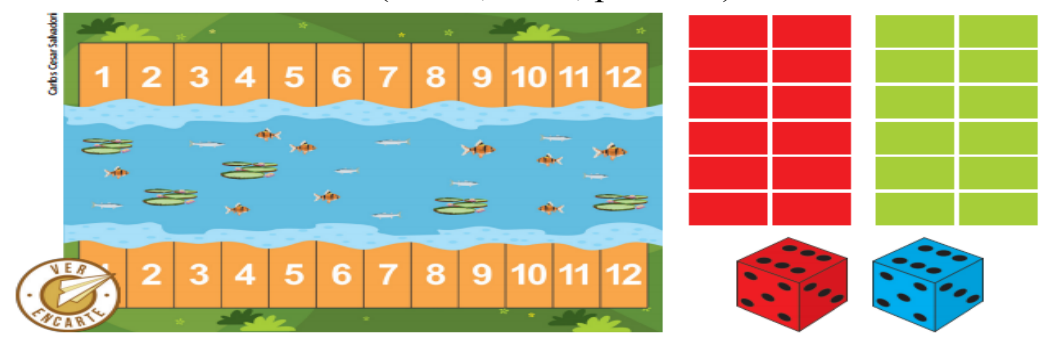

No nosso recorte, temos como objetivo, analisar as compreensões de crianças acerca de alguns aspectos da probabilidade em situações de jogo, especificamente do jogo Travessia do Rio.

Nosso foco abrange, especialmente, o espaço amostral e a aleatoriedade, que correspondem às duas primeiras exigências cognitivas apontadas por Bryant e Nunes (2012). Assim, para tais autores, o espaço amostral é visto como o conjunto completo de possibilidades em um problema de probabilidade e a análise do espaço amostral exige raciocínio combinatório. Já a aleatoriedade está

In: M.A. Sorto (Ed.), Advances in statistics education: developments, experiences and assessments. Proceedings of the Satellite conference of the International Association for Statistical Education (IASE), July 2015, Rio de Janeiro, Brazil. 
relacionada à incerteza, ou seja, sabe-se o que poderá vir a acontecer, mas não com exatidão o que realmente acontecerá, pois os eventos dessa natureza ocorrem de forma aleatória, nãodeterminística.

\section{MÉTODO}

Para compor o estudo piloto, os participantes selecionados foram três crianças da rede pública de ensino dos anos iniciais do Ensino Fundamental: uma de 6 anos do $1^{\circ}$ ano (denominaremos aqui de $\mathrm{C} 1$ ), uma de 8 anos do $3^{\circ}$ ano (identificaremos como $\mathrm{C} 2$ ) e uma de 10 anos do $5^{\circ}$ ano (chamaremos de $\mathrm{C} 3$ ).

Fizemos uma entrevista áudio gravada, do tipo clínica, que segundo Carraher (1998, p.1718) "visa buscar as respostas mais características do pensamento do sujeito, aquelas que o sujeito dá com maior convicção não com maior rapidez". A autora completa, afirmando que há pessoas que têm a necessidade de refletir sobre alternativas diferentes para encontrarem a resposta que consideram a mais correta; a ênfase do método recai sobre o processo que leva o sujeito a dar uma ou outra resposta. Deve-se, pois, considerar o estudo dos processos para se analisar a complexidade e a sofisticação do pensamento da criança.

$\mathrm{Na}$ elaboração das perguntas que nortearam a entrevista clínica, consideramos indagações que orientassem para alguns conhecimentos específicos de probabilidade: análise de chance igual e de chance diferente de ocorrência de um evento, evento impossível, evento pouco provável, espaço amostral, eventos equiprováveis, independência de eventos e aleatoriedade.

Assim sendo, os questionamentos iniciais que nortearam a entrevista, foram:

1- Pedro apostou todas as fichas no 2 e João todas no 12 . Quem tem mais chance de ganhar? Por quê? (Análise de chance igual)

2- João colocou todas as suas fichas no 1. Ele conseguirá ganhar o jogo? Por quê? (Evento impossível)

3- Quem tem mais chance de ganhar o jogo: uma pessoa que apostou todas as fichas no 7 ou quem apostou todas no 11 ? Por quê? (Análise de chance diferente)

4- Pedro apostou todas as fichas no 3. Ele tem muita, pouca ou nenhuma chance de ganhar o jogo? Por quê? (Evento pouco provável)

5- João apostou todas as fichas no 8. Quais números podem sair nos dados para dar 8? (Espaço amostral)

6- André jogou o dado vermelho algumas vezes e o resultado foi sempre o 5. Se ele jogar novamente você acha que poderá sair o 5 novamente? Por quê? (Independência de eventos)

7- Se você jogar com o dado vermelho e eu com o dado azul quem terá mais chance de tirar o 6: eu ou você? Por quê? (Eventos equiprováveis)

8- Se eu jogar um dado, é mais fácil sair qual dos números? Por quê? (Aleatoriedade)

As entrevistas foram feitas individualmente com cada criança. As regras do jogo foram explicitadas e realizadas algumas jogadas para familiarização do aluno com o jogo. Foram oferecidos à criança, lápis e papel para possível registro, especialmente o que se refere ao item 5 (espaço amostral).

\section{ANÁLISES} observados.

Para fins de análises, as entrevistas foram transcritas e os registros dos alunos foram

Em relação ao primeiro questionamento que envolvia a comparação de chance igual de ocorrência de um evento, as crianças menores consideraram que quem teria mais chance de ganhar o jogo seria a pessoa que estivesse com o 12 e justificaram afirmando "porque ela tá no 12 e o 12 tem mais", diz C2, "o 12 vai ganhar e o 2 não ganha" $(\mathrm{C} 1)$. Já C3 afirma que vai sair o 12 porque é o número da sorte. Indagado sobre a possibilidade de sair o 2, ele (C3) afirma que não pode com dois dados resultar no dois, no entanto durante discussão da questão seguinte, ele constata seu equívoco e muda sua resposta.

- Mas você antes disse que dois não podia e agora pode? Comenta a pesquisadora, retomando uma resposta anterior do entrevistado.

- Pode (mostra um e um nos dados). 
- Agora voltando pra pergunta anterior quem teria mais chance de ganhar: quem colocou no 2 ou no 12 ?

- Esse daqui (aponta para o dois).

- $O$ do dois agora? Agora mudou por quê?

- Porque podia cair esses dois (mostra um e um)

- E o do doze podia cair como?

- Assim (mostra seis e seis)

- E quem era que tinha mais chance de ganhar?

- Os dois.

- Mas você tinha dito antes que era o doze e agora são os dois? Por quê?

- Ah porque esse tem a mesma chance que esse (apontando para o 2 e o 12 do jogo).

No diálogo, constata-se que C3 mudou de postura e de opinião. Reconsiderou sua resposta, pois "alguns sujeitos podem mesmo ter a necessidade de examinar algumas alternativas diferentes antes de encontrarem a resposta que julgam mais apropriada". (CARRAHER, 1998, p.18).

Em resposta ao item que trata de evento impossível, C1 afirma que é possível passar para o outro lado do rio, com um dado. A criança é lembrada que o jogo é com dois dados e é desafiada a formar o um com os dois dados. Ela não sabe justificar e afirma "porque passa e pronto".

Já C2, responde: "Não. Porque tá no 1. Porque o 1 é muito fraco. Porque é só 1 e não é 2. Ele tem menos". Novamente relaciona ganhar com que tem mais, com o número maior. O 1 tem menos, por isso não ganha.

C3 é categórico e não apresenta dúvidas: "Não. Porque se cair 1 não tem como. Só se fosse um dado. Se fosse dois dados ia ser "dois" (o resultado).

Parece-nos óbvia a percepção de eventos impossíveis, mas, ao menos para as crianças mais novas entrevistadas, essa constatação não é tão clara. Outros fatores parecem influenciar os resultados, como foi observado nas respostas: $\mathrm{C} 1$ confirma que só pode obter $1 \mathrm{com}$ um dado, mas se nega a admitir que é um evento impossível, enquanto $\mathrm{C} 2$ faz uma relação de tamanho e força, afirmando que o 1 é pequeno e é fraco, por isso não sairá no lançamento de dados.

No que tange ao item que compara chances diferentes, $\mathrm{C} 1$ e $\mathrm{C} 2$ afirmam que ganha o 11, justificando respectivamente que: "ganha quem tá no 11 " e "porque o 11 tem mais valor do que o 7". Observa-se que os argumentos de C1 são sustentados na própria crença de que aquela é a resposta correta, enquanto $\mathrm{C} 2$ se apoia na lógica de quem tem mais, ganha.

$\mathrm{O}$ entrevistado $\mathrm{C} 3$ diz que quem escolheu o 7 tem mais chance de ganhar porque é mais difícil cair o 5 e o 6 , mostrando nos dados. Ele alega que vai sempre cair mais os números menores 2, 3, 4 que os números maiores ( 5 e 6) por esta razão tem mais chance de sair o 7 que é formado por números menores.

Esta questão possibilita a reflexão sobre o espaço amostral, considerando as possibilidades de se formar o 7 e o 11 no lançamento de dois dados. Bryant e Nunes (2012) afirmam que o reconhecimento de todos os eventos que compõem o espaço amostral é uma condição essencial para a compreensão da natureza da probabilidade e, consequentemente, da resolução de problemas envolvendo probabilidade. Observamos que $\mathrm{C} 3$ responde corretamente e até dá algum indicativo de que percebe esse espaço amostral, mas não consegue vislumbrá-lo em sua totalidade. Estudos anteriores, apontados no relatório de Bryant e Nunes (2012), informam que grande parte dos erros que crianças e também adultos fazem do raciocínio probabilístico dizem respeito a uma compreensão limitada do espaço amostral, razão pela qual, acreditamos que haja a necessidade de uma intervenção para que alunos como $\mathrm{C} 3$ evoluam no conceito e compreensão do espaço amostral.

Quando indagados se alguém que apostou todas as fichas no 3 teria muita, pouca ou nenhuma chance de ganhar o jogo, C3 diz: "Pouquíssima. Porque não vai cair direto assim (mostra 2 e 1). Tem que errar..." $\mathrm{C} 1$ diz que tem pouca chance e justifica dizendo "porque tem". C2 diz que não tem nenhuma chance, porque não dá para fazer o 3 (lança os dados, conta e conclui que não é possível). Novamente $\mathrm{C} 3$ demonstra um pensamento mais elaborado e aponta o 2 e 1 (como parte do espaço amostral), embora não fique claro, com apenas esta questão, se ele tem o entendimento de que 2 e 1 e 1 e 2 são diferentes possibilidades de se chegar a 3, ou seja, há dois modos se de obter 3 com dois dados. 
Para apresentar o espaço amostral formado pela soma dos dados que resultam em 8, C1 diz que não sabe, mas é incentivada pela pesquisadora a fazer algumas tentativas contando nos dados. Ela conta e diz: "Nesse tem 4 e nesse tem 4" e afirma que tem mais modos de dar oito. Conta 6 e 2 e escreve. A pesquisadora insiste: tem mais jeito? Ela diz que não.

C2 testa algumas combinações, contando nos dados e diz que não tem como dar 8 . Tenta mais algumas vezes e chega em 5 e 3 . Afirma que não tem mais modos de dar oito.

Já C3 chega a três combinações: $4+4,5+3$ e $6+2$. Mais uma vez, C3 não deixa claro se consegue perceber que $3+5$ e $5+3$, bem como $6+2$ e $2+6$, são combinações diferentes para o mesmo resultado. Perguntado se tem outros modos, ele diz que não.

Todos os participantes tiveram dificuldade em perceber mais de uma possibilidade de combinação para o resultado 8. Foi necessário o incentivo da pesquisadora para que pensassem, testassem, contassem e constatassem se haveria ou não outras possiblidades.

Bryant e Nunes (2012) alertam para a questão complexa referente ao espaço amostral e dizem que a relação não é linear entre duas variáveis (por exemplo, se aumentar o número de dados, ou o número de lançamentos) e que a completa falta de estudos de intervenção sobre métodos de ensino de como formar espaços amostrais é a diferença mais gritante na investigação sobre a compreensão das crianças sobre probabilidade.

Ao tratar da independência de eventos, $\mathrm{C} 1$ e $\mathrm{C} 2$ recaem no erro denominado recência positiva, motivados pela crença de que os eventos recentes continuarão se repetindo, afirmando que se sempre caiu 5, vai cair 5 novamente, enquanto $\mathrm{C} 3$ comete o erro de recência negativa, que considera que ocorrerá um evento diferente, afirmando que não vai cair o 5 porque já caiu muitas vezes. Embora admita que haja a possibilidade de cair, ele não acredita que caia e atribui à sorte ou ao azar.

Resultados semelhantes envolvendo independência de eventos foram apontados por Bryant e Nunes (2012) que afirmaram que, em pesquisa recente de Chiesi e Primi (2009), constatou-se que crianças tendem a cometer mais o erro de recência positiva e adultos o de recência negativa.

Em relação às questões que tratam de eventos equiprováveis (item 7), C3 não concebe a equiprobabilidade, associando o resultado do lançamento do dado a seu desejo, a sua vontade. $\mathrm{O}$ diálogo abaixo aponta esta perspectiva:

- Se você jogar com o dado vermelho e eu com o dado azul quem terá mais chance de tirar o 6: eu ou você?

- Eu. Porque eu tô jogando e estou querendo ganhar.

- E se eu quiser ganhar também?

- Ai fica empatado.

- Então quem tem mais chance de sair 6: o meu ou o seu dado?

- O meu, porque eu estou com mais vontade de ganhar.

- E se eu tiver com mais vontade que você?

- Você ganha.

- Mas você acha que vai sair o 6 no meu?

- Acho que sim ou não. O meu vai sair o 6 com certeza porque eu estou com muita vontade.

Por fim, ele explica que vontade é você ficar torcendo muito para que caia o 6 e ficar pedindo na mente para sair.

C2 diz que ela tem mais chance porque joga na parte do seis, ou seja, joga para cair o seis. "Não pode cair igual. Eu tenho mais chance de ganhar". C1 se contradiz, mas não explica, diz que é a pesquisadora quem tem mais chance, depois diz que é ela própria.

$\mathrm{Na}$ última questão que trata de aleatoriedade, quando questionado sobre qual número tem mais chance de sair no lançamento de um dado, $\mathrm{C} 3$ diz que seria o 5 , porque é o número da sorte e o número que ele estaria torcendo, mas admitiu que se ninguém tivesse torcendo poderia cair qualquer número, mostrando que quando ele dissocia os eventos do jogo, percebe melhor a aleatoriedade.

Viali (2008) afirma que a ideia de fenômenos aleatórios, sem causa definida, ainda hoje encontra dificuldade para serem aceitos com naturalidade. Outrora era atribuído às divindades e ainda hoje os espaços de mídia atribuem importância a pessoas que supostamente preveem o futuro. 
Percebe-se que os estudantes mais novos têm grande dificuldade em conceber a aleatoriedade. $\mathrm{C} 1$ diz que o 6 tem mais chance de sair porque o 6 ganha, ele ganha muito, enquanto $\mathrm{C} 2$ acha que 5 tem mais chance. Ele marcava só o 5 quando estava jogando, voltando a evidenciar também a falta de compreensão acerca da independência de eventos.

Bryant e Nunes (2012) citam Fischbein (1987) que afirma que as crianças em idade préescolar possuem intuições primárias sobre a natureza dos eventos incertos, aleatórios, baseados em suas experiências informais, mas nem sempre essas intuições são coerentes e levam a equívocos por parte das crianças. No entanto, elas são a base para o progresso das crianças na compreensão da probabilidade e, com a ajuda do ensino, podem reconstruir as ideias iniciais em intuições secundárias, muito mais aprofundadas sobre a probabilidade.

\section{CONSIDERAÇÕES FINAIS}

É natural, considerando os dados apresentados por Bryant e Nunes (2012), que as crianças mais velhas tenham um melhor desempenho probabilístico que as mais novas. O que se observou, no entanto, foi que a qualidade das respostas apresentadas por $\mathrm{C} 1$, de 6 anos, se aproximaram das de $\mathrm{C} 2$, de 8 anos, com uma diferença: quase nunca, $\mathrm{C} 1$ conseguia justificar suas escolhas, colocando os argumentos num nível muito pessoal: "porque sim", "porque...", "porque tem".

$\mathrm{O}$ aluno denominado $\mathrm{C} 3$, o mais velho do grupo, apresentou justificativas mais consistentes e quando era confrontado com incoerências em seu discurso, voltava atrás e modificava sua linha de raciocínio, alterando suas respostas. Podemos dizer que ele aprendeu com a experiência ao longo do percurso da entrevista, e esse processo foi valorizado, como apontado por Carraher (1998).

No que diz respeito ao espaço amostral, percebemos no grupo entrevistado, que há uma dificuldade real de percepção de todos os eventos que o compõem, consequentemente houve dificuldade das crianças para fazer uma lista exaustiva. Nesse sentido, ao que tudo indica, os entrevistados não conseguem perceber que, por exemplo, o evento 3 e 4 é diferente de 4 e 3 .

A relação de $\mathrm{C} 3$ com o jogo o fez classificar, quase sempre, os eventos aleatórios em escolhas regidas pela força do pensamento, pela sorte ou pelo azar, atributos próprios que permeiam o senso comum em relação aos jogos de azar.

Importante pontuar que os alunos entrevistados apresentaram potencial para expandir suas compreensões probabilísticas, fazendo uso de jogos. Concordamos com Bryant e Nunes (2012) que apontam a necessidade de uma intervenção escolar com vistas à ampliação da compreensão da probabilidade, em especial no que diz respeito à aleatoriedade e ao espaço amostral.

\section{REFERÊNCIAS}

Brasil. (2014). Secretaria de Educação Básica. Pacto Nacional pela Alfabetização na Idade Certa: Jogos na Alfabetização Matemática. Ministério da Educação. Diretoria de Apoio à Gestão Educacional. Brasília: MEC, SEB, 2014.

Bryant, P., \& Nunes, T. (2012) Children's understanding of probability: a literature review. Nuffield Foundation. Disponível em http://www.nuffieldfoundation.org/sites/default/files/files/Nuffield_CuP_FULL_REPORTv_F INAL.pdf. Acessado em 22.09.2014.

Carraher, T. N. (1998). O método clínico usando os exames de Piaget. 5. Ed. São Paulo: Cortez.

Luvison, C. da C., \& Santos, C. A. (2013). Estatística e Probabilidade: a resolução de problemas a partir do jogo Travessia do rio. In: XI Encontro Nacional de Educação Matemática - XI ENEM, 2013, Curitiba. Educação Matemática: Retrospectivas e Perspectivas. Curitiba: Sociedade Brasileira de Educação Matemática, v. 1.

Viali, L. (2008). Algumas Considerações Sobre a Origem da Teoria da Probabilidade. Revista Brasileira de História da Matemática. V. 8, p. 85-97, 2008. Disponível em http://www.academia.edu/1308131/Algumas_Considera\%C3\%A7\%C3\%B5es_sobre_a_Orige m_da_Teoria_da_Probabilidade 